\title{
Comparison of Bobath based and movement science based treatment for stroke: a randomised controlled trial
}

\author{
P $M$ van Vliet, N B Lincoln, A Foxall
}

See Editorial Commentary, p 465

J Neurol Neurosurg Psychiatry 2005;76:503-508. doi: 10.1136/jnnp.2004.040436

See end of article for authors' affiliations

.....................

Correspondence to: Dr Paulette M van Vliet, Division of Rehabilitation and Ageing, School of Community Health Sciences, University of Nottingham B Floor, Medical School, Queen's Medical Centre, Nottingham NG7 2UH, UK; paulette.vanvliet@ ntlworld.com

Received 1 March 2004 Revised version received 12 July 2004 Accepted

10 September 2004
Objectives: Bobath based (BB) and movement science based (MSB) physiotherapy interventions are widely used for patients after stroke. There is little evidence to suggest which is most effective. This single-blind randomised controlled trial evaluated the effect of these treatments on movement abilities and functional independence.

Methods: A total of 120 patients admitted to a stroke rehabilitation ward were randomised into two treatment groups to receive either BB or MSB treatment. Primary outcome measures were the Rivermead Motor Assessment and the Motor Assessment Scale. Secondary measures assessed functional independence, walking speed, arm function, muscle tone, and sensation. Measures were performed by a blinded assessor at baseline, and then at 1, 3, and 6 months after baseline. Analysis of serial measurements was performed to compare outcomes between the groups by calculating the area under the curve (AUC) and inserting AUC values into Mann-Whitney $U$ tests.

Results: Comparison between groups showed no significant difference for any outcome measures. Significance values for the Rivermead Motor Assessment ranged from $p=0.23$ to $p=0.97$ and for the Motor Assessment Scale from $p=0.29$ to $p=0.87$.

Conclusions: There were no significant differences in movement abilities or functional independence between patients receiving a BB or an MSB intervention. Therefore the study did not show that one approach was more effective than the other in the treatment of stroke patients.
M ost people who suffer movement problems caused by stroke receive physiotherapy. ${ }^{12}$ There is evidence that physiotherapy improves physical abilities, over and above spontaneous recovery, as two meta-analyses have reported significant improvements in independence in activities of daily living and reduction in impairments for higher intensities of physiotherapy. ${ }^{3}$ The optimal type of physiotherapy for patients with stroke is unclear. The present study compares the effectiveness of two different physiotherapy treatments.

Research to identify the most effective content of physiotherapy has taken two main directions: either examining the effectiveness of specific treatment interventions or the effectiveness of treatment approaches based on particular theories. The first has met with some success, where interventions such as increased amounts of practice with techniques to facilitate learning of motor skills, ${ }^{5}$ treadmill training with body weight support, ${ }^{6}$ constraining the intact upper limb, ${ }^{7}$ and task specific practice, ${ }^{8}$ have reduced impairment compared to controls. Research on treatment approaches has usually compared one treatment with another, rather than with a "no intervention" control, because of the practical difficulties in withholding treatment.

Comparisons of Bobath, proprioceptive neuromuscular facilitation, Rood, and conventional treatments ${ }^{9-11}$ have shown no significant differences in outcomes. These trials have been criticised for lacking key requirements of a well controlled study including evaluation by a blind assessor, randomisation, and sample sizes determined by power calculation, for late intervention of too short duration, ${ }^{12}{ }^{13}$ and for using measures not specific to motor impairments. In a single case experimental design comparing neurodevelopmental and Brunstrom treatment, walking speed improved more in the Brunstromm treatment for only one out of seven patients, but this result did not generalise to other gait parameters or upper arm function measures. ${ }^{14}$

Two widely practised treatment approaches ${ }^{15} 16$ are the Bobath based (BB) treatment ${ }^{17}{ }^{18}$ and a framework based on the movement sciences ("motor relearning"), outlined by Carr and Shepherd. ${ }^{19}$ Differences between these two treatments have been demonstrated in a study where the content of treatment delivered to patients was examined. ${ }^{21}$ Langhammer and Stanghelle compared the treatments in a randomised controlled trial. ${ }^{22}$ In contrast to some earlier studies, this trial used a blind assessor, included impairment measures, and determined sample size by power calculation and treatment began early and was continued for as long as the patient was hospitalised. There were significant differences between the treatments in impairment measures at 2 weeks after random allocation, and also in length of stay, in favour of the motor relearning group. A recent systematic literature search of trials investigating the effectiveness of the Bobath approach ${ }^{23}$ found that two case series and one controlled trial reported positive results, one non-controlled trial, three controlled trials, and one randomised controlled trial reported negative results, and the remaining studies showed no differences between compared groups. The author concluded that the results showed no evidence proving the effectiveness of the Bobath approach, but neither did they show evidence of non-efficacy, due to the methodological limitations of the studies reviewed.

The aim of the present study was to evaluate whether BB or movement science based (MSB) treatment was more effective in improving the movement abilities and functional independence of patients following stroke.

Abbreviations: $A U C$, area under the curve; $B B$, Bobath based; MAS, Motor Assessment Scale; MSB, movement science based 


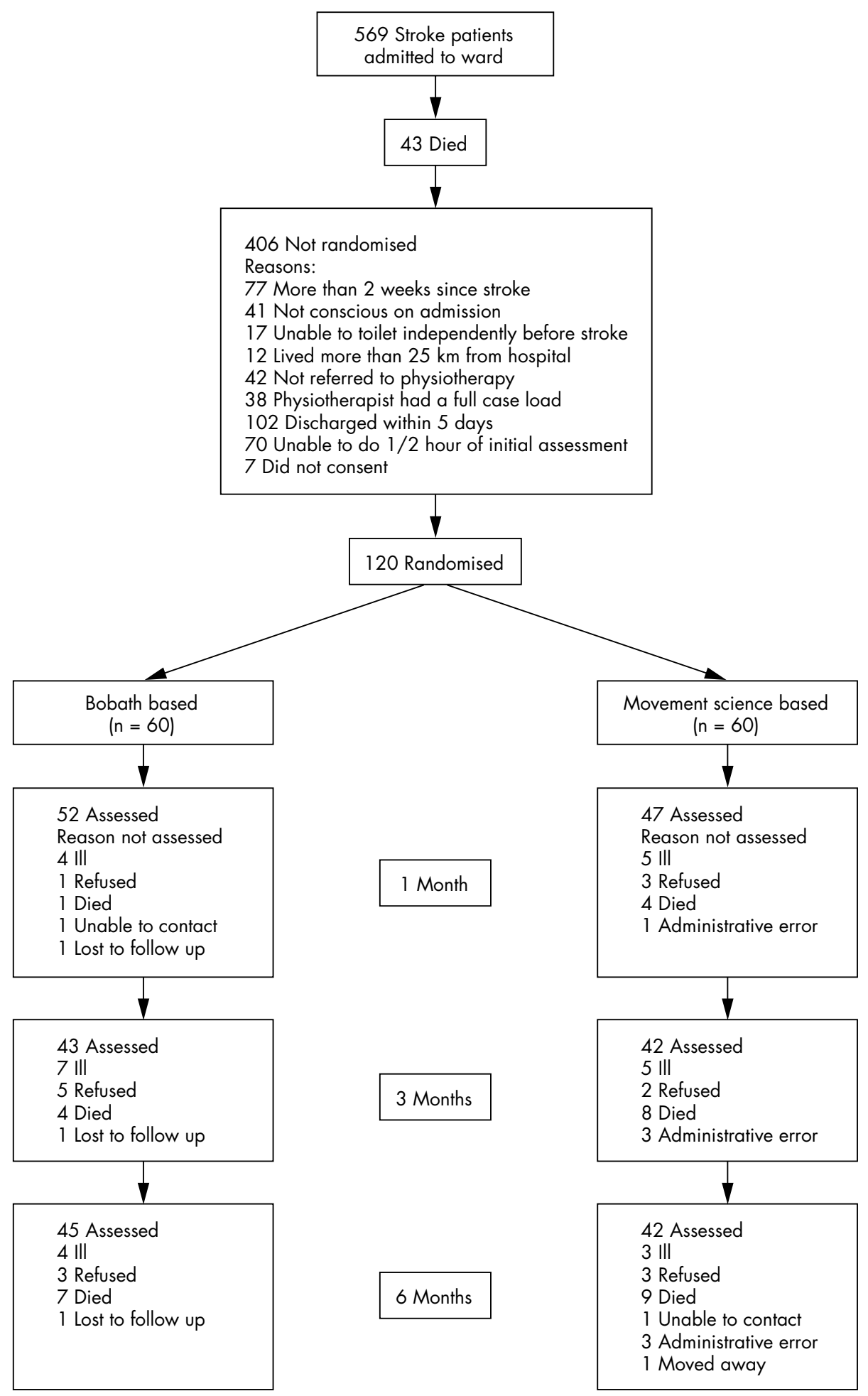

Figure 1 Progress of patients through the trial.

\section{METHODS}

Approval for the study was granted by the hospital ethics committee. Stroke patients admitted consecutively to a stroke rehabilitation ward over a period of 21 months were considered for inclusion in the study. The inclusion criteria were a diagnosis of stroke and referral to physiotherapy. Patients were excluded if they were more than 2 weeks post stroke, unconscious on admission to hospital, unable to toilet themselves independently prior to their stroke, living more than $25 \mathrm{~km}$ from the hospital, unable to tolerate more than half an hour of the physical tasks required in the initial assessment, or did not give informed consent. Patients were not recruited if the physiotherapists were unable to see more patients at the time. Baseline characteristics were recorded 
from the patients' medical notes, including age, gender, side of stroke, and type of stroke according to the Bamford classification. $^{24}$

Patients were randomly allocated to one of two treatment groups. One group received a BB treatment, ${ }^{17}{ }^{18} 25$ the other an MSB treatment. ${ }^{19}{ }^{26-28}$ Prior to randomisation, treatment was the routine $(\mathrm{BB})$ treatment. Following randomisation, which occurred within 2 weeks following the stroke, the two treatments were delivered by different groups of physiotherapists using prepared written guidelines, consisting of theoretical concepts for practice and main clinical objectives, based on their own knowledge and experience and their interpretation of the literature. Different physiotherapy assistants were available to assist physiotherapists for each treatment group.

The BB treatment was delivered by physiotherapists working on the ward who used it routinely before the study began. MSB treatment was provided by two physiotherapists who received training because they had insufficient experience of the treatment. The first author $(\mathrm{PvV})$ provided the training, some outpatient MSB treatment, and holiday and illness cover for MSB therapists. The amount of daily treatment was matched to the amount given by existing ward physiotherapists. Ward occupational therapists also used the allocated treatment. Patients received the allocated treatment during outpatient physiotherapy. Treatment continued for as long as was needed, rather than a standardised

Table 1 Biographical characteristics

\begin{tabular}{|c|c|c|c|}
\hline & BB & MSB & Comparison* $p$ \\
\hline \multicolumn{4}{|l|}{ Age } \\
\hline Mean & 73.3 & 75 & \multirow[t]{2}{*}{0.34} \\
\hline SD & 10.4 & 9.1 & \\
\hline \multicolumn{4}{|l|}{ Gender } \\
\hline Male & 27 & 33 & \multirow{2}{*}{0.27} \\
\hline Female & 33 & 27 & \\
\hline \multicolumn{4}{|c|}{ Hemisphere affected } \\
\hline Right & 29 & 27 & \multirow[t]{3}{*}{0.81} \\
\hline Left & 30 & 31 & \\
\hline Bilateral & 1 & 2 & \\
\hline \multicolumn{4}{|c|}{ Bamford classification } \\
\hline TACS & 9 & 8 & \multirow[t]{5}{*}{0.76} \\
\hline PACS & 29 & 32 & \\
\hline LACS & 14 & 11 & \\
\hline POCS & 4 & 6 & \\
\hline Unsure & 4 & 3 & \\
\hline \multicolumn{4}{|c|}{ Sheffield Screening Test } \\
\hline Median & & 16 & \multirow[t]{2}{*}{0.11} \\
\hline IQR & $13-19$ & $12-18$ & \\
\hline \multicolumn{4}{|l|}{ Story Recall } \\
\hline Immediate & & & \\
\hline Median & 18 & 15 & \multirow[t]{2}{*}{0.96} \\
\hline IQR & $6-29$ & $7-34$ & \\
\hline \multicolumn{4}{|l|}{ Delayed } \\
\hline Median & 12 & 12 & \multirow[t]{2}{*}{0.52} \\
\hline IQR & $0-23$ & $0-30$ & \\
\hline \multicolumn{4}{|c|}{ Star cancellation } \\
\hline Median & 51 & 52 & \multirow[t]{2}{*}{0.79} \\
\hline IQR & $46-54$ & $48-54$ & \\
\hline \multicolumn{4}{|c|}{ Rey figure copy } \\
\hline Immediate & & & \\
\hline Median & & & \multirow[t]{2}{*}{0.78} \\
\hline IQR & $10-30$ & $10-29$ & \\
\hline \multicolumn{4}{|l|}{ Delayed } \\
\hline Median & 7 & 6.5 & \multirow{2}{*}{0.95} \\
\hline IQR & $1-13$ & $1-14$ & \\
\hline
\end{tabular}

*Comparison using $t$ test for age, Mann-Whitney $U$ for cognitive tests, and $\chi^{2}$ for gender, hemisphere affected, and Bamford classification. $B B$, Bobath based treatment; IQR, inter-quartile range; $M S B$, movement science based treatment; $S D$, standard deviation; TACS, total anterior circulation infarct; PACS, partial anterior circulation infarct; LACS, lacunar infarct; POCS, posterior circulation infarct. length of time, because of the varying needs of patients and to reflect usual hospital practice.

The primary outcome measures were the Rivermead Motor Assessment ${ }^{29}$ and the Motor Assessment Scale (MAS), ${ }^{30}$ which measure the consequences of motor impairment. The first was developed by therapists using the BB treatment and the second was developed by therapists using the MSB treatment. Secondary measures were the ten hole peg test, ${ }^{31}$ the $6 \mathrm{~m}$ walk test, ${ }^{32}$ and the Modified Ashworth Scale. ${ }^{33}$ The Nottingham Sensory Assessment ${ }^{34}$ was used to measure sensory impairment. Measures of activities of daily living were the Barthel Index ${ }^{35}$ and Extended Activities of Daily Living scale. ${ }^{36}$

One month following randomisation, patients were assessed on four other baseline variables using the Sheffield Screening Test for Acquired Language Disorders, ${ }^{37}$ Rey figure copy, ${ }^{38}$ Star cancellation test, ${ }^{39}$ and Story Recall ${ }^{40}$ as measures of cognitive impairment. The 1 month delay was necessary because of the long length of the initial assessment.

The power calculation indicated that with a significance level of 0.05 and a power of $80 \%$ it would be possible to detect a difference of two points on the Rivermead Motor Assessment gross function section with 78 patients. The estimated standard deviation was obtained from a previous randomised controlled trial which recruited from a similar stroke population, using similar criteria. ${ }^{41}$

Allocation to treatment groups was by a computer generated random sequence provided by a therapist not involved with the trial, with notification delivered in opaque, sealed envelopes. Blocked randomisation was used to ensure approximately equal numbers of patients in each group at any time. Patients were screened consecutively on admission to the ward and those that met the inclusion criteria were referred for initial assessment. After the initial assessment was completed, a research therapist opened the next envelope and informed the therapists providing the treatments of the group allocation.

Outcome assessments were completed at 1, 3, and 6 months after random allocation by an assessor who was blind to the group allocation. The assessor's training consisted of repeated supervised practice of the assessments prior to the trial. To ensure masking, assessments of inpatients occurred in a room separate from the ward and patients were brought to the assessor there whenever possible. Patients were asked not to mention their treatment or therapist to the assessor. For later examination of the success of masking, the assessor recorded a guess of the patient's group allocation at each assessment.

\section{Statistical analyses}

Biographical characteristics were compared using MannWhitney $U$ tests (ordinal data), $t$ tests for independent samples (interval data), or $\chi^{2}$ tests (nominal data). Outcomes between the two groups were compared using an analysis of serial measurements utilising the area under the curve (AUC). This summary measure is calculated by adding the areas under the graph (where outcome score is plotted against time) between each pair of consecutive observations, for each outcome measure, for each subject. The AUC values of the groups were then compared using Mann-Whitney U tests. Matthews et al ${ }^{42}$ argue that this approach is more appropriate than the usual approach to assessing the difference between sets of repeated measurements, which is to apply separate significance tests at each measurement time point. The main reasons are that when each time point is analysed separately, the individual's response over time is ignored, initial differences in baseline scores are not taken into account, and the value at one time point is likely to influence successive time points so the significance tests will 
not be independent. Thus a summary measure is preferred. The AUC is calculated as follows:

$$
\begin{aligned}
\text { AUC }= & \frac{\mathrm{W}_{1}{ }^{*}\left(\mathrm{~h}_{1}+\mathrm{h}_{2}\right)}{2}+\frac{\mathrm{w}_{2}{ }^{*}\left(\mathrm{~h}_{2}+\mathrm{h}_{3}\right)}{2} \\
& +\frac{\mathrm{W}_{3}{ }^{*}\left(\mathrm{~h}_{3}+\mathrm{h}_{4}\right)}{2}
\end{aligned}
$$

where $h_{1}$ is baseline score, $h_{2}$ is score at $l$ month, $h_{3}$ is score at 3 months, $\mathrm{h}_{4}$ is score at 6 months, and $\mathrm{w}_{1}$ is time elapsed between initial and first assessment ( 1 month), $\mathrm{w}_{2}$ is time elapsed between first and second assessment (2 months), and $w_{3}$ is time elapsed between second and third assessment (3 months).

Some of the data could not be included in this procedure either because an assessment had been missed or the assessment scale used had insufficient measurement points. Therefore, to include all possible data in the analysis, additional Mann-Whitney $U$ tests were performed to compare groups at the single time points of 1,3 , and 6 months, bearing in mind that this particular analysis was subject to the problems described above. ${ }^{42}$ All statistical procedures were performed with the SPSS version 11 .

\section{RESULTS}

A total of 569 were patients admitted to the stroke ward during the period of the trial. Of these, 120 patients were recruited and randomly allocated. Reasons for exclusions are shown in the trial profile in fig l. Comparison of the groups showed no significant difference in number of patients assessed at 1 month $\left(\chi^{2}=6.2, \mathrm{p}=0.41\right), 3$ months $\left(\chi^{2}=7\right.$, $\mathrm{p}=0.22)$, or 6 months $\left(\chi^{2}=4.5, \mathrm{p}=0.72\right)$. The groups were not significantly different in age, gender, side of stroke, type of lesion, or cognitive impairments (table 1). At baseline, the BB group had higher median scores for the gross function and leg and trunk sections of the Rivermead Motor Assessment, and the supine to side lying, supine to sitting, balanced sitting, and sit to stand sections of the MAS (table 2). The MSB group had a higher median score for the upper arm section of the MAS (table 2).

Patients received a median $23 \mathrm{~min}$ of treatment by a physiotherapist per weekday (IQR 13-32 min). The median total number of minutes of treatment by a physiotherapist was 365 (IQR 140-1160). There was no significant difference between the groups in the amount of treatment $(p=0.62)$. The BB group spent more time with the physiotherapy assistant with physiotherapist also present $(\mathrm{p}=0.0001)$, but the MSB group spent more time with the assistant alone $(\mathrm{p}=0.0001)$.

The $\mathrm{\kappa}$ statistic was used to assess agreement between the assessor's guesses and the actual group allocation. The $\kappa$ value was 0.22 , indicating poor agreement. Outcome measures were completed on 99 patients at 1 month, 85 patients at 3 months, and 87 patients at 6 months. The results of the two groups are summarised in tables 2 and 3. The statistical analysis was by intention-to-treat.

Comparison of the AUC showed no significant difference between the groups for any of the outcome measures. Comparison of outcomes at single time points with MannWhitney $U$ tests showed a small number of differences. At

\begin{tabular}{|c|c|c|c|c|c|c|c|c|c|c|c|c|}
\hline \multirow[b]{2}{*}{ Measure } & \multicolumn{2}{|c|}{ Baseline } & \multicolumn{2}{|c|}{1 month } & \multirow[b]{2}{*}{ Comp. $\mathrm{p}^{*}$} & \multicolumn{2}{|c|}{3 month } & \multirow[b]{2}{*}{ Comp. $p$} & \multicolumn{2}{|c|}{6 month } & \multirow[b]{2}{*}{ Comp. p } & \multirow{2}{*}{$\frac{\text { AUC }}{\text { Comp. } p}$} \\
\hline & BB & MSB & BB & MSB & & BB & MSB & & BB & MSB & & \\
\hline \multicolumn{13}{|c|}{ Rivermead Motor Assessment } \\
\hline \multicolumn{13}{|c|}{ Gross function } \\
\hline Median & 2 & 1 & 7 & 6 & 0.49 & 7 & 8 & 0.18 & 8 & 8 & 0.61 & 0.41 \\
\hline IQR & $1-6$ & $1-4$ & $3-9$ & $2-9$ & & $4-10$ & $6-10$ & & $6-10$ & $6-10$ & & \\
\hline \multicolumn{13}{|c|}{ Leg and trunk } \\
\hline Median & 4 & 2 & 7 & 5 & 0.61 & 7 & 7 & 0.52 & 7 & 7 & 0.41 & 0.23 \\
\hline IQR & $1-8$ & $1-5$ & $1-9$ & $1-9$ & & $0-9$ & $1-10$ & & $3-9$ & $0-9$ & & \\
\hline \multicolumn{13}{|l|}{ Arm } \\
\hline Median & 4 & 4 & 8 & 8 & 0.87 & 9 & 8 & 0.79 & 10 & 8 & 0.64 & 0.97 \\
\hline IQR & $0-9$ & $0-9$ & $4-10$ & $1-12$ & & $0-12$ & $4-12$ & & $3-12$ & $2-12$ & & \\
\hline \multicolumn{13}{|l|}{ MAS } \\
\hline \multicolumn{13}{|c|}{ Supine to side lying } \\
\hline Median & 4 & 1 & 6 & 4 & 0.09 & 6 & 5 & 0.82 & 6 & 4 & 0.11 & 0.58 \\
\hline IQR & $0-6$ & $0-6$ & $2-6$ & $0-6$ & & $1-6$ & $2-6$ & & $3-6$ & $1-6$ & & \\
\hline \multicolumn{13}{|c|}{ Supine to sitting } \\
\hline $\begin{array}{l}\text { Median } \\
Q R\end{array}$ & 4 & 2 & 6 & 6 & 0.5 & 6 & 6 & 0.51 & 6 & 6 & $0.0067 \dagger$ & 0.87 \\
\hline \multicolumn{13}{|c|}{ Balanced sitting } \\
\hline Median & 5 & 4 & 5 & 5 & 0.49 & 5 & 5 & 0.8 & 5 & 5 & 0.25 & 0.29 \\
\hline IQR & $2-5$ & $2-5$ & $4-6$ & $5-6$ & & $4-6$ & $4-6$ & & $4-6$ & $3-6$ & & \\
\hline \multicolumn{13}{|c|}{ Sitting to stand } \\
\hline Median & 2 & 1 & 5 & 5 & 0.77 & 5 & 5 & 0.28 & 5 & 5 & 0.54 & 0.31 \\
\hline IQR & $1-4$ & $1-2$ & $2-6$ & $1-6$ & & $1-6$ & $2-6$ & & $2-6$ & $2-6$ & & \\
\hline \multicolumn{13}{|l|}{ Walking } \\
\hline Median & 0 & 0 & 3 & 3 & 0.28 & 3 & 4 & 0.55 & 4 & 3 & 0.27 & 0.77 \\
\hline IQR & $0-2$ & $0-1$ & $1-5$ & $0-4$ & & $2-5$ & $3-5$ & & $3-5$ & $2-5$ & & \\
\hline \multicolumn{13}{|l|}{ Upper arm } \\
\hline Median & 3 & 4 & 5 & 4 & 0.74 & 5 & 5 & 0.69 & 5 & 5 & 0.53 & 0.66 \\
\hline IQR & $0-5$ & $1-5$ & $1-5$ & $1-6$ & & $1-6$ & $2-6$ & & $2-6$ & $1-6$ & & \\
\hline \multicolumn{13}{|c|}{ Hand movements } \\
\hline Median & 3 & 3 & 5 & 5 & 0.45 & 5 & 5 & 0.76 & 6 & 5 & 0.14 & 0.82 \\
\hline IQR & $0-5$ & $0-6$ & $0-6$ & $2-6$ & & $0-6$ & $3-6$ & & $3-6$ & $0-6$ & & \\
\hline \multicolumn{13}{|c|}{$\begin{array}{l}\text { Advanced hand } \\
\text { activities }\end{array}$} \\
\hline $\begin{array}{l}\text { activities } \\
\text { Median }\end{array}$ & 0 & 0 & 1 & 1 & 0.71 & 2 & & 0.95 & & & 0.23 & 030 \\
\hline IQR & $0-3$ & $0-3$ & $0-6$ & $0-6$ & 0.11 & & $1-6$ & & $1-6$ & $0-6$ & 0.23 & \\
\hline
\end{tabular}

Table 2 Comparison of primary outcome measures

AUC, Area under the curve; BB, Bobath based treatment; Comp., Comparison; IQR, interquartile range; MSB, movement science based treatment *Comparison with Mann-Whitney U test; tsignificant. 
Table 3 Comparison of secondary outcome measures

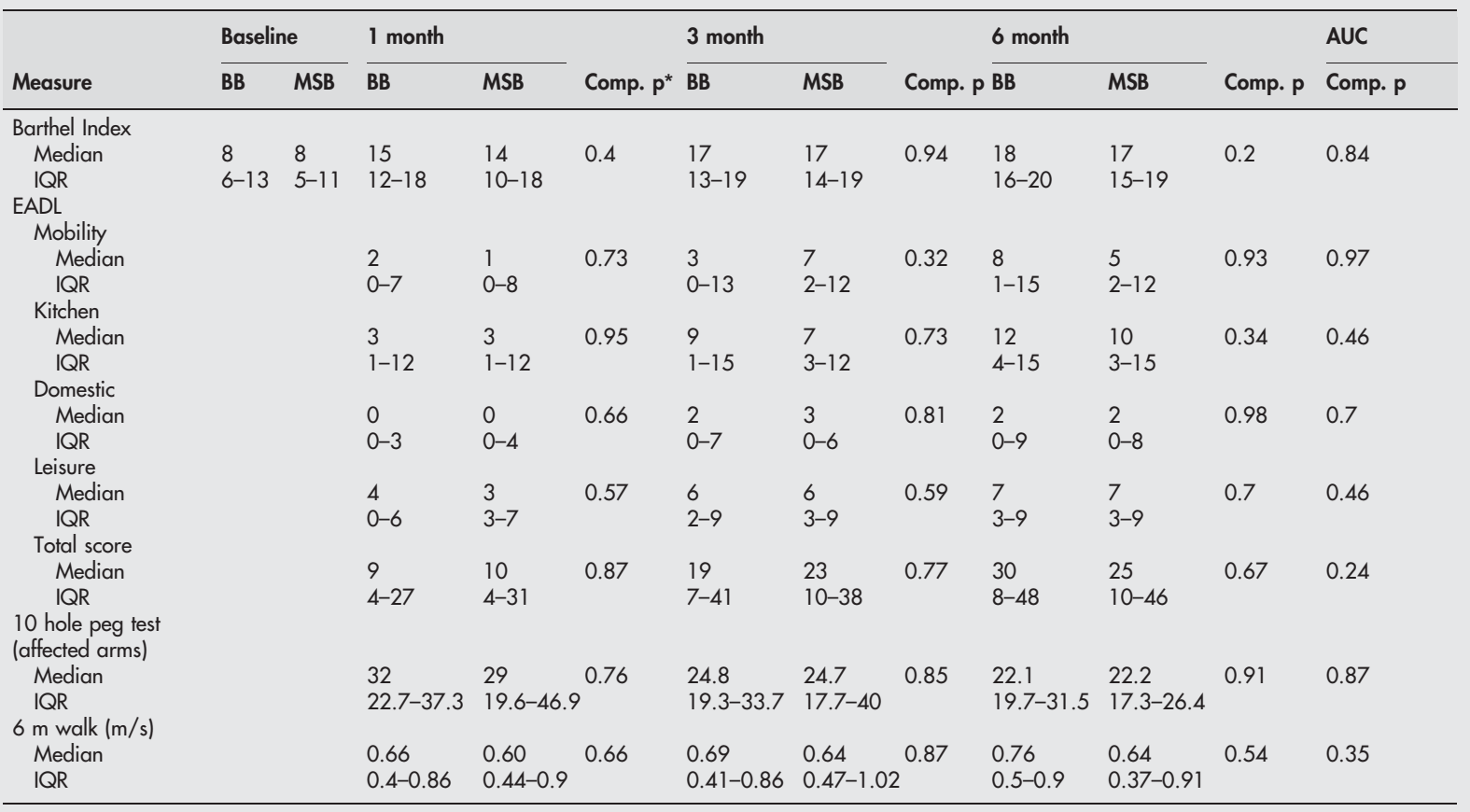

*Comparison with Mann-Whitney $U$ test.

AUC, Area under the curve; BB, Bobath based treatment; Comp., Comparison; EADL, Extended Activities of Daily Living scale; IQR, interquartile range; MSB, movement science based treatment.

6 months, there was a statistically significant difference on the supine to sitting section of the MAS, in favour of the BB group (table 2). There was a statistically significant difference on the "go out socially" item of the leisure section of the Extended Activities of Daily Living scale $(p=0.032)$, and on the bathing section of the Barthel Index $(p=0.034)$, at 1 month, in favour of the MSB group (table 3). There were no significant differences between the groups for muscle tone or sensation. Bonferroni correction was used to counter the use of multiple subgroup analyses, and none of the above differences between the groups were significant.

There were no significant differences in number of days in hospital ( $U=1398, p=0.87$ ) or place of discharge $\left(\chi^{2}=4.88\right.$, $p=0.08)$. The statistical analyses were repeated with the exclusion of five patients who did not receive a sufficient amount of their allocated treatment. The pattern of results was the same.

\section{DISCUSSION}

The results indicate equivalent outcomes in patients receiving a BB or an MSB treatment. The few statistically significant differences could all be attributed to chance.

Our results differ from those of Langhammer and Stanghelle ${ }^{22}$ who found a shorter length of stay and a higher summed MAS score and a higher score on the arm section of the Sødring Motor Evaluation scale 2 weeks after random allocation for their motor relearning group.

One reason for our different results could be that treatment was more intensive ( 40 min per day) in the previous study. Beneficial effects of increased intensity of therapy have been found in one meta-analysis ${ }^{3}$ and a number of randomised controlled trials. ${ }^{43-46}$ Also, treatment began earlier in the previous study, at 3 days after stroke, whereas in the present study treatment began at a variable time within the first 2 weeks. Therefore, it may be the combination of early, ${ }^{22}$ more intensive treatment with the motor relearning principles that is more effective. Another reason is the possibility that differences in initial status influenced the results in the previous study. The motor relearning group had higher initial median scores on the MAS, the arm section of the Sødring Motor Evaluation scale, and the Barthel Index. Although no significant differences were detected at baseline, there was no correction for initial status in their comparison of outcome, so the possibility that initial abilities influenced the results remains. Also, the content of their treatments may differ from the present study. Motor relearning treatment was based on a text from 1987, ${ }^{19}$ whereas we used more recent publications. ${ }^{19}{ }^{26-28} 4748 \mathrm{BB}$ treatment was also based on more publications ${ }^{18} 25$ 49-51 than in the previous study.

Limitations of the present study were that a single environment served both treatments, so that it was sometimes difficult to implement changes to the environment to suit both treatments at once, and also there was the risk of treatment contamination. However, the content of a sample of the treatments ${ }^{21}$ demonstrated preservation of several key differences between the treatments. The intensity of treatment may have been too low to demonstrate any differences between groups. The dose was determined by the necessity to match the dose to the typical amount in the hospital, so that intensity would not be a confounding variable in our comparison between groups. Our analyses comparing groups at 1, 3, and 6 months may have been influenced by initial differences between the groups. The AUC comparison which did correct for initial differences may not have had sufficient power to detect differences $(n=70)$. The therapists were not experts in these treatments but were representative of current practice. There were more therapists delivering $\mathrm{BB}$ treatment as physiotherapists employed by the hospital were required to move between departments at specified intervals.

Despite improvements in this trial design compared to some previous studies, no significant differences were detected. Although examination of the effectiveness of specific treatment interventions has had more success, it remains important to evaluate the effectiveness of whole treatment approaches, because it is in this context that specific treatments are delivered to patients. Examination of 
specific treatments in isolation does not allow study of the interaction of different treatment elements. It is recommended that further investigations of treatment combinations increase the dose of therapy to match intensities in those studies examining specific interventions with positive results. In the case of the upper limb, for example, positive results have been found for as little as 15-40 min of extra therapy per day, ${ }^{43-46}$ although evidence is conflicting. ${ }^{52}$ It is also recommended that future trials comparing these two treatments recruit a larger number of patients, to increase the power to detect any differences between them. Since no differences between approaches were found in this study, it is possible that other factors such as dose and timing are more important than the treatment given. For the present, our results indicate that physiotherapists may choose to use either BB or MSB treatment as neither was found to be more effective than the other.

\section{ACKNOWLEDGEMENTS}

The authors gratefully acknowledge the financial support of the Stroke Association, UK. We would like to express our gratitude to all the therapists and therapy assistants involved in patient treatment and data collection, particularly Melanie Parker, Wendy Goodenough, Melissa Clements, Patricia Moore, Sarah Lockwood, Tracy Whiteley, and members of the physiotherapy and occupational therapy staff at the participating hospital. We would also like to thank Michael Dewey for statistical advice, John Gladman for his support as ward consultant, and Jules Becher for comments on the manuscript.

\section{Authors' affiliations}

P M van Vliet, Division of Stroke Medicine, University of Nottingham, Nottingham, UK

N B Lincoln, School of Psychology, University of Nottingham, Nottingham, UK

A D Foxall, Division of Stroke Medicine, University of Nottingham, Nottingham, UK

This study was funded by the Stroke Association, UK

Competing interests: none declared

\section{REFERENCES}

1 Wade DT, Wood VA, Langton-Hewer R. Recovery after stroke-the first 3 months. J Neurol Neurosurg Psychiatry 1985;48:7-13.

2 Brocklehurst J, Andrews K, Richards B, et al. How much physical therapy for patients with stroke? BMJ 1978;1:45-9

3 Kwakkel G, Wagenaar RC, Koelman TW, et al. Effects of intensity of rehabilitation after stroke. Stroke 1997;28:1550-6.

4 Langhorne $\mathbf{P}$, Wagenaar RC, Partridge C. Physiotherapy after stroke: more is better? Physiother Res Int 1996;1:75-88.

5 Sunderland A, Tinson D, Bradley L, et al. Arm function after stroke. An evaluation of grip strength as a measure of recovery and a prognostic indicator. J Neurol Neurosurg Psychiatry 1989;52:1267-72.

6 Visintin M, Barbeau $H$, Lorner-Bitensky $N$, et al. A new approach to retrain gait in stroke patients through body weight support and treadmill stimulation. Stroke 1998;29:1122-8.

7 Van der Lee JH, Wagenaar RC, Lankhorst GJ, et al. Forced use of the upper extremity in chronic stroke patients: results from a single blind randomised controlled trial. Stroke 1999;30(11):2369-75.

8 Dean CM, Shepherd RB. Task-related training improves performance of seated reaching tasks after stroke. Stroke 1997;28(4):722-8.

9 Dickstein R, Hockerman S, Pillar T, et al. Stroke rehabilitation: three exercise therapy approaches. Phys Ther 1986;66:1233-8.

10 Loggigian MK, Samuels MS, Falconer J, et al. Clinical exercise trial for stroke patients. Arch Phys Med Rehabil 1983;64:364-7.

11 Lord JP, Hall K. Neuromuscular reeducation versus traditional programs for stroke rehabilitation. Arch Phys Med Rehabil 1986;67:88-91.

12 Ernst E. A review of stroke rehabilitation and physiotherapy. Stroke 1990;21:1081-5.

13 Ashburn A. Physiotherapy in the rehabilitation of stroke: a review. Clin Rehabil 1993;7:337-45.

14 Wagenaar RC, Meijer OG, van Wieringen CW, et al. The functional recovery of stroke: a comparison between neuro-developmental treatment and the Brunstrom method. Scand J Rehabil Med 1990;22:1-8.
15 Nilsson L, Nordholm L. Physical therapy in stroke rehabilitation: bases for Swedish physiotherapist's choice of treatment. Physiother Theory Pract 1992;8:49-55.

16 Davidson I, Waters K. Physiotherapists working with stroke patients. Physiotherapy 2000;86(2):69-80

17 Bobath B. Adult hemiplegia. Evaluation and treatment, 3rd ed. Oxford: Heinemann Medical, 1990.

18 Davies P. Right in the middle. Heidelberg: Springer, 1991.

19 Carr JH, Shepherd RB. A motor relearning programme for stroke. London: Heinemann Physiotherapy, 1987

20 Carr JH, Shepherd RB. Neurological rehabilitation: optimising motor performance. Oxford: Butterworth-Heinemann, 1998.

21 van Vliet PM, Lincoln NB, Robinson E. Comparison of the content of two physiotherapy approaches for stroke. Clin Rehabil 2000;15:398-414.

22 Langhammer B, Stanghelle JK. Bobath or Motor Relearning Programme? A comparison of two different approaches of physiotherapy in stroke rehabilitation: a randomized controlled study, Clin Rehabil 2000;14:361-9.

23 Paci M. Physiotherapy based on the Bobath concept for adults with post-stroke hemiplegia: a review of effectiveness studies. J Rehabil Med 2003;35:2-7.

24 Bamford J, Sandercock P, Dennis M, et al. Classification and natural history of clinically identifiable subtypes of cerebral infarction. Lancet 1991;337:1521-6.

25 Davies PM. Steps to follow: a guide to the treatment of adult hemiplegia. Heidelberg: Springer, 1985

26 Carr JH, Shepherd RB. Movement Science: foundations for physical therapy in rehabilitation. London: Heinemann Physiotherapy, 1987.

27 Carr JH, Shepherd RB. A motor learning model for stroke rehabilitation. Physiotherapy 1989;89:372-80.

28 Carr JH, Shepherd RB. Reflections on physiotherapy and the emerging science of movement rehabilitation. Aust J Physiother, 1994;40th Jubilee, 39-47.

29 Lincoln NB, Leadbitter D. Assessment of motor function in stroke patients. Physiotherapy 1979;65:48-51.

30 Carr JH, Shepherd RB, Nordholm L, et al. Investigation of a new motor assessment scale for stroke patients. Phys Ther 1985;65(2):175-80.

31 Turton AJ, Fraser CM. A test battery to measure the recovery of voluntary movement following stroke. Int Rehabil Med 1986;8:74-9.

32 Wade DT, Hewer RL, Skilbeck CE, et al. Stroke: a critical approach to diagnosis, treatment and management. London: Chapman and Hall, 1985.

33 Bohannon RW, Smith MB. Interrater reliability of a Modified Ashworth Scale of muscle spasticity. Phys Ther 1987;2:206-7.

34 Jackson J, Crow L. The reliability of sensory assessments in hemiplegia. Paper presented at the Eleventh Congress of the World Confederation for Physical Therapy, 1991, London.

35 Collin C, Wade DT, Davies S, et al. The Barthel ADL Index, a reliability study. Int Disabil Stud 1988;10:61-3.

36 Nouri FM, Lincoln NB. An extended activities of daily living scale for stroke patients. Clin Rehabil 1987;1:301-5

37 Syder D, Body R, Parker M, et al. Sheffield Screening Test for Acquired Language Disorders. Windsor: NFER Nelson, 1993.

38 Rey A. Le test, de copie de figure complexe. Paris: Editions Centre de Psychologie Applique, 1959

39 Wilson B, Cockburn J, Halligan PW. Behavioural Inattention Test. Titchfield Hampshire: Thames Valley Test Company, 1987.

40 Wilson BA, Cockburn J, Baddeley A. The Rivermead Behavioural Memory Test, Bury St. Edmunds, Suffolk: Thames Valley Test Company, 1985.

41 Juby LC, Lincoln NB, Berman P. The effect of a stroke rehabilitation unit on functional and psychological outcome: a randomised controlled trial. Cerebrovasc Dis 1996:6:106-10.

42 Matthews JNS, Altman DG, Campbell MJ, et al. Analysis of serial measurements in medical research. BMJ 1990;300:230-5.

43 Platz T, Winter T, Muller N, et al. Arm ability training for stroke and traumatic brain injury patients with mild arm paresis: a single-blind, randomized, controlled trial. Arch Phys Med Rehabil 2001;82:961-8.

44 Feys HM, Weerdt WD, Selz BE, et al. Effect of a therapeutic intervention for the hemiplegic upper limb in the acute phase after stroke. A single-blind, randomized, controlled multicenter trial. Stroke 1998;29:785-92.

45 Sunderland A, Tinson D, Bradley L, et al. Enhanced physical therapy for arm function after stroke. J Neurol Neurosurg Psychiatry 1992;55:530-5.

46 Kwakkel G, Wagenaar RC, Twisk JWR, et al. Intensity of leg and arm training after primary middle-cerebral artery stroke: a randomised trial. Lancet 1999:354:191-6.

47 Ada L, Canning C. Key issues in neurological physiotherapy. London: Heinemann Medical, 1990

48 Carr JH, Shepherd RB. Spasticity: research findings and implications for intervention. Physiotherapy 1995:81:421-9.

49 Kidd G, Lawes N, Musa I. Understanding neuro-muscular plasticity. London: Edward Arnold, 1992.

50 Mulder T. A process-oriented model of human motor behaviour: toward a theory based rehabilitation approach. Phys Ther 1991;71:157-64.

51 Rottke K. From reflex to skill-the training of co-ordination. Arch Phys Med Rehabil 1980;61:551-61.

52 Lincoln NB, Parry RH, Vass CD. Randomized, controlled trial to evaluate increased intensity of physiotherapy treatment of arm function after stroke. Stroke 1999;30:573-9. 